\title{
Suplementação com ferro injetável em cordeiros infectados experimentalmente por Haemonchus contortus
}

Valeska Paula Casanova ${ }^{[a]}$, Adelina Rodrigues Aires ${ }^{[a]}$, Alexia Pretto ${ }^{[a]}$, João Francisco Tadielo Limana ${ }^{[a]}$, Gustavo Potrich Marchioretto ${ }^{[a]}$, Brunna de Mattos Granja ${ }^{[a]}$, Silvana Giacomini Collet ${ }^{[a]}$, Alexandre Krause ${ }^{[b]}$, Rafael Costa Ebling ${ }^{[a]}$, Marta Lizandra do Rêgo Leal[a]"

\footnotetext{
[a] Departamento de Grandes Animais, Clínica de Ruminantes, Universidade Federal de Santa Maria (UFSM), Santa Maria, RS, Brasil

[b] Departamento de Pequenos Animais, Laboratório de Patologia Clínica Veterinária, Universidade Federal de Santa Maria (UFSM), Santa Maria, RS, Brasil
}

*Autor correspondente

e-mail: martalizandra@gmail.com

\section{Resumo}

A anemia causada pela infecção por parasitas gastrintestinais causa grandes perdas econômicas na criação de ovinos. 0 objetivo deste estudo foi avaliar o efeito da suplementação injetável de ferro dextrano sobre variáveis sanguíneas e metabolismo do ferro em cordeiros infectados experimentalmente pelo Haemonchus contortus. Foram utilizados 24 cordeiros machos, cruza Corriedale e Texel, com média de $17 \mathrm{Kg}$ de peso vivo e 4 meses de idade. Os animais foram distribuídos em quatro grupos com seis animais cada: Grupo não infectado e não tratado com ferro (G1); Grupo infectado e tratado com ferro (G2); Grupo não infectado e tratado com ferro (G3); e Grupo infectado e não tratado (G4). Os grupos 2 e 4 receberam 10.000 larvas de H. contortus (L3), via oral, divididas em três doses, com intervalo de dois dias entre cada infecção. Os cordeiros do G2 e G3 receberam três doses de $20 \mathrm{mg} / \mathrm{kg}$ de ferro dextrano, por via intramuscular, com intervalo de sete dias entre aplicações. As coletas de sangue e fezes foram realizadas nos dias 10 (D10), 17 (D17), 24 (D24) e 31 (D31). No sangue foi analisado o eritrograma e número de reticulócitos. Mediante o número de hemácias, hemoglobina e hematócrito, calculou-se os índices hematimétricos: volume corpuscular médio (VCM) e concentração de hemoglobina corpuscular média (CHCM). 0 metabolismo do ferro foi determinado mediante análise dos teores séricos de ferro, da ferritina, da transferrina, do índice de saturação da transferrina, da capacidade de ligação total do ferro (CLTF) e dos estoques de ferro medular. A contagem de ovos por grama de fezes (OPG) foi determinada nos mesmos momentos experimentais. O OPG foi negativo nos grupos 1 e 3 durante o período experimental. Nos dias 24 e 31, os valores de OPG foram semelhantes nos grupos 2 e 4.0 número total de hemácias, hematócrito e hemoglobina foram menores no 
D24 e D31 nos grupos infectados em relação àqueles não infectados. No entanto, no D31, os animais do G2 exibiram maiores valores do Ht e Hb em relação aos animais do G4. Maiores contagens de reticulocitos foram obtidas no G2 e G4. Não houve diferença no VCM entre os grupos e observou-se maiores valores numéricos do CHCM nos grupos G1 e G3 no D31. Os cordeiros do grupo infectado e não tratado (G4) apresentaram menores teores séricos de ferro no D31 em relação aos demais grupos. Maiores valores de transferrina e CTLF foram observados nos animais não suplementados com ferro. As reservas de ferro na medula óssea foram superiores nos animais tratados com ferro. A suplementação com ferro injetável reduz a gravidade da anemia provocada pela infecção por Haemonchus contortus em cordeiros, bem como mantém os estoques deste mineral na medula óssea, viabilizando a síntese de hemoglobina. 